\title{
A comparative morphological study of Thymelaeaceae in Korea
}

\author{
Jae-Jin Lee and Sang-Hun Oh* \\ Department of Biology, Daejeon University, Daejeon 34520, Korea \\ (Received 10 August 2017; Revised 19 August 2017; Accepted 22 September 2017) \\ 한국산 팥꽃나무과의 비교형태학적 연구 \\ 이재진 · 오상훈* \\ 대전대학교 생명과학과
}

\begin{abstract}
Thymelaeaceae in Korea includes ten species in five genera (Daphne, Diarthron, Edgeworthia, Stellera, and Wikstroemia). This study investigated the morphology of these species using herbarium specimens and fresh materials obtained during fieldwork to understand the variation level and to delineate each taxon in the family. Our comparative morphological analysis showed that the Korean taxa in Thymelaeaceae were easily distinguished based on their morphologies. It is easy to distinguish Daphne from Wikstroemia when the Korean taxa are considered. However, Daphne genkwa is morphologically similar to Wikstroemia based on the leaf arrangement, pubescence of the leaves, and the ovary shape. The results here suggest that further systematic studies of the Daphne group using more data are necessary.
\end{abstract}

Keywords: Morphology, Daphne, Wikstroemia, Thymelaeaceae

적 요: 한국산 팥꽃나무과 분류군 5속 10종(Daphne속 5종, Diarthron속 1종, Edgeworthia속 1종, Stellera속 1 종 및 Wikstroemia속 2종)에 대해 비교형태학적 연구를 수행하였다. 야외 조사와 국내외 주요 표본관에 소장 된 표본을 이용하여 팥꽃나무의 주요 형태형질을 정의하고, 변이의 폭을 파악하여, 각 분류군의 한계를 설정 하고 유연관계를 추론하였다. 그 결과 한국산 팥꽃나무과 분류군들은 형태형질에 의해서 뚜렷이 구분되었다. 팥꽃나무속의 경우 한국산 분류군만 고려하면 산닥나무속과 쉽게 구분되었으나, 팥꽃나무 $(D . g e n k w a)$ 는 잎 의 배열과 털의 분포 및 자방의 형태에 있어서 산닥나무속과 공통적인 특징을 보이고 있었다. Daphne group 에 대해 보다 많은 분류군과 다른 종류의 형질분석을 통하여 자세한 연구가 필요한 것으로 사료된다.

주요어: 팥꽃나무속, 산닥나무속, 형태, 팥꽃나무과

팥꽃나무과(Thymelaeaceae Juss.)는 아욱목(Malvales)에 속하는 상록성 또는 낙엽성 식물로서, 교목, 관목, 덩굴식 물 또는 드물게 초본식물로 구성되어 있다(Herber, 2003). 전 세계적으로 약 45속의 650-800 여 종을 포함하며, 북반 구 및 남반구의 온대와 열대지방에 넓게 분포하지만, 대 부분의 속과 종들은 남반구에 집중적으로 분포한다 (Mabberley, 1997; Herber, 2003; Wang et al., 2007). 팥꽃나 무과의 식물은 대부분 독성을 지니고 있으나, 화려하고
향기가 나는 꽃이 아름다워서 팥꽃나무속(Daphne L.) 및 Pimelea Banks ex Gaertn. 등의 속에 속하는 식물들은 원예 용으로 널리 재배되며, 산닥나무속(Wikstroemia Endl.)과 삼지닥나무속(Edgeworthia Meisn.)의 식물들의 수피는 화 폐를 비롯한 고품질의 종이를 만드는 데 원료로 쓰인다 (Hamaya, 1955; Herber, 2003).

팥꽃나무과에 대한 분류체계는 다양하게 제시되어 왔 다. Bentham and Hooker (1880)는 팥꽃나무과 38속을 자방

*Author for correspondence: soh42@dju.kr 
의 구조, 밑씨의 수, 열매의 종류 등의 형질을 바탕으로 3 개의 족(Aquilarieae, Euthymelaeeae, Phalerieae)으로 나누 고, 이 중 Euthymelaeeae족을 꽃의 특징에 따라 3 개의 열 (series)로 구분하였다. Domke (1932)는 팥꽃나무과 6속 11 종(Aquilaria Lam. 1종, Gyrinops Gaertn. 1종, Lophostoma (Meisn.) Meisn. 1종, Craterosiphon Engl. \& Gilg 3종, Schoenobiblus Mart. 1종, Wikstroemia 4종)을 새로 기재하고, 형태형질 연구를 통해 팥꽃나무(Daphne genkwa Siebold \& Zucc.)을 비롯한 4속 23종(Daphne 11종, Farreria Balf. f. \& W. W. Sm. ex Farrer 1종, Pentathymelaea Lecomte 1종, Stellera L. 10종)을 산닥나무속(Wikstroemia)으로 분류할 것 을 제안하였다. 그리고 Hamaya (1955)는 일본산 분류군 5 개 속(Daphne, Daphnimorpha Nakai, Diplomorpha Meisn., Edgeworthia 및 Wikstroemia)에 대해 가지의 분지, 화반 (disk), 소화경 마디 형태, 줄기와 잎의 체관부 형태, 화분의 형태 등에 대한 연구 결과 팥꽃나무속(Daphne)을 세분하 여 Daphne, Daphnanthoides 및 Genkwa절로 분류한 바 있다. Takhtajan (1997)은 팥꽃나무과를 팥꽃나무목(Thymelaeales) 으로 인식한 후 팥꽃나무과(Thymelaeaceae)와 Gonystylaceae 로 분류하였으나, 대부분의 현대 분류체계는 팥꽃나무과 를 하나의 과로 인식하고 있다. 그러나 팥꽃나무과를 4 개 의 아과(Aquilarioideae, Gilgiodaphnoideae, Gonystyloideae 및 Thymelaeoideae)로 분류하거나(Domke, 1934; Heywood, 1993) 2 개의 아과(Thymelaeoideae 및 Octolepidoideae)로 인 식하는(Herber, 2003) 등 과 내 분류체계는 학자 간에 이견 이 있다. 한편, Herber (2003)는 생장 형태, 해부학적 형태, 화서 구조, 꽃의 구조, 발생학적 특징, 핵형, 화분 형태학적 특징, 열매 형태 등에 근거해 상기한 2 개 아과 내에 유연관 계가 가까운 속들을 묶어 비공식적인 속집단을 추가적으 로 제시하였는데, 이들은 Daphne group 14속, Gnidia group 9속, Gonystylus group 6속, Linostoma group 9속, Octolepis group 5속 및 Phaleria group 2속이다. 과 수준에서의 계통 학적 연구는 아프리카와 오스트레일리아의 분류군을 중 심으로 27속 41종을 대상으로 엽록체 $r b c L$ 및 $\operatorname{trnL}-\operatorname{trnF}$ 구 간을 이용한 계통학적 연구가 있으며, Heywood (1993)가 제시한 4 개의 아과가 각각 단계통군임을 보여주었다(Van der Bank et al., 2002).

한편, 한국산 팥꽃나무과 분류군은 5 속 10 종(팥꽃나무 속[Daphne] 5종, 아마풀속[Diarthron] 1종, 삼자닥나무속 [Edgeworthia] 1종, 피뿌리풀속[Stellera] 1종, 산닥나무속 [Wikstroemia] 2종)으로 알려져 있는데(Hong et al., 1999; Lee, 2003; Hong, 2007; Lee et al., 2013), 이들에 대한 계통 학적 및 비교형태학적 연구는 미흡하다. 특히, 팥꽃나무 속과 산닥나무속은 잎의 배열, 화서의 유형, 화반의 형태 에 의해 구분되고 있으나(Wang et al., 2007), 이들 형질이 두 속을 뚜렷이 구분하지 못해 두 속의 분류학적 한계는 학자들 간에 이견이 있어 왔다. 예를 들어, Domke (1932)는 한국산 분류군 중 팥꽃나무(Daphne genkwa Siebold \&
Zucc.)를 산닥나무속으로 변경할 것을 제안한 반면, Hamaya (1955)와 대부분의 학자들은 이를 팥꽃나무속에 분류하였다. Jung and Hong (2003b)은 잎 표피 미세구조에 대한 연구 결과 팥꽃나무 $(D . g e n k w a)$ 가 팥꽃나무속의 다 른 종들과 뚜렷이 구분되나 연구에 포함된 산닥나무속의 2종과 유사함을 밝힌 바 있다. 최근, Lee et al. (2013)은 백 서향나무(D. kiusiana Miq.)로 인식되어 왔던 제주도산 개 체들이 장타원형(oblong)의 잎과 화탁통(hypanthium)이 무 모인 특징을 들어 제주백서향나무(D. jejudoensis M. Kim) 로 신종 기재하였다. 그러나 한반도에 분포하는 모든 종 을 대상으로 자세한 비교형태학적 연구는 현재까지 수행 되지 않았다.

따라서 본 연구에서는 한국산 분류군들을 대상으로 비 교형태학적 연구를 수행하여 이들 분류군의 한계 및 유연 관계를 파악하고 각 분류군의 분류학적 실체를 규명하고 자 하였다.

\section{재료 및 방법}

본 연구에서는 한국산 팥꽃나무과 분류군 5 속 10 종(팥 꽃나무속 5종, 아마풀속 1종, 삼지닥나무속 1종, 산닥나무 속 2종, 피뿌리풀 1종)을 대상으로 하였다. 2014년 7월부 터 2015년 8월까지 한반도 내 자생지(경기, 강원, 충북, 전 북, 전남, 경남, 제주)에서 채집한 재료와, 국립생물자원관 (KB) 및 국립산림과학원 난대아열대산림연구소(WTFRC) 표본관으로부터 대여 받은 표본 등 약 210여 점을 포함하 여 사용하였다(Appendix 1). 또한, 일본 국립자연사박물관 (TNS)을 방문하여 상기한 종 및 그 근연종의 표본을 조사 하였다. 연구 기간 중 채집한 개체들은 석엽표본으로 제 작하거나 FAA(formalin-acetic acid-alcohol) 용액으로 고정 해 액침표본으로 제작하여 대전대학교 생명과학과 표본 관(TUT)에 소장하였다. 팥꽃나무과 분류군들의 형태형질 의 비교 분석은 습성, 줄기의 분지 양상, 잎의 배열, 형태, 크기 및 털의 유무, 엽병의 털 유무, 화서의 형태, 화탁통 색깔 및 털, 악편의 수, 수술의 수, 자방의 형태, 화반 형태 등의 주요 형질을 선정하여 수행하였다.

\section{결 과}

한국산 팥꽃나무과 분류군들의 습성, 줄기의 분지 양상 및 털 유무, 잎의 배열과 형태, 잎의 크기, 잎의 털 유무, 화서 의 형태, 꽃의 세부기관 등 각 형질별 특징은 다음과 같다.

\section{습성(habit)}

한국산 팥꽃나무과 분류군들은 관목이거나 초본중 하 나의 습성을 나타내었다. 관목은 낙엽관목과 상록관목, 초 본은 1 년생과 다년생의 유형이었으며, 각 분류군별로 하나 의 습성만 나타냈다. 낙엽관목에 해당되는 분류군들은 팥 
꽃나무(Daphne genkwa), 두메닥나무(Daphne pseudomezereum var. koreana (Nakai) Hamaya), 삼지닥나무(Edgeworthia chrysantha Lindl.), 거문도닥나무(Wikstroemia ganpi (Siebold \& Zucc.) Maxim.) 및 산닥나무(Wikstroemia trichotoma (Thunb.) Makino)가 이에 해당되었다. 반면 상록관목은 제주백서향 나무(Daphne jejudoensis), 백서향나무(Daphne kiusiana)와 서 향나무(Daphne odora Thunb.)로 나타났다. 1년생 초본은 아 마풀(Diarthron linifolium Turcz.)로 관찰되었으며, 다년생 초 본은 피뿌리풀(Stellera chamaejasme L.)로 나타났다.

\section{줄기(stem)}

1. 줄기의 분지 양상: Hamaya(1955)는 일본산 팥꽃나무
과 분류군을 분류하는 형태형질 중 하나로 줄기의 분지 양상을 제시한 바 있다. 이 연구에 따르면 화서의 위치, 줄 기 분지 방향, 줄기 분지 갈래 수, 줄기 분지 시기, 줄기가 분지하는 슈트정단부의 위치를 종합해 일본산 분류군의 줄기 분지 양상을 6 가지 유형으로 구분하였다. 한국산 팥 꽃나무과 분류군에서는 총 5 개의 유형이 나타났는데, 각 유형과 과 내의 분류체계가 일치하지 않았다. Wikstroemia type (Hamaya, 1955)은 잎이 대생하고 화서가 줄기 끝에 총 상으로 달리며 결실기에 열매를 맺고 화서가 떨어진 자리 에서 이듬해 새로운 줄기가 두 갈래로 분지하는 유형으로 팥꽃나무(D. genkwa)와 산닥나무(W. trichotoma)에서 관찰 되었다(Fig. 1A). 반면에 Diplomorpha type (Hamaya, 1955)
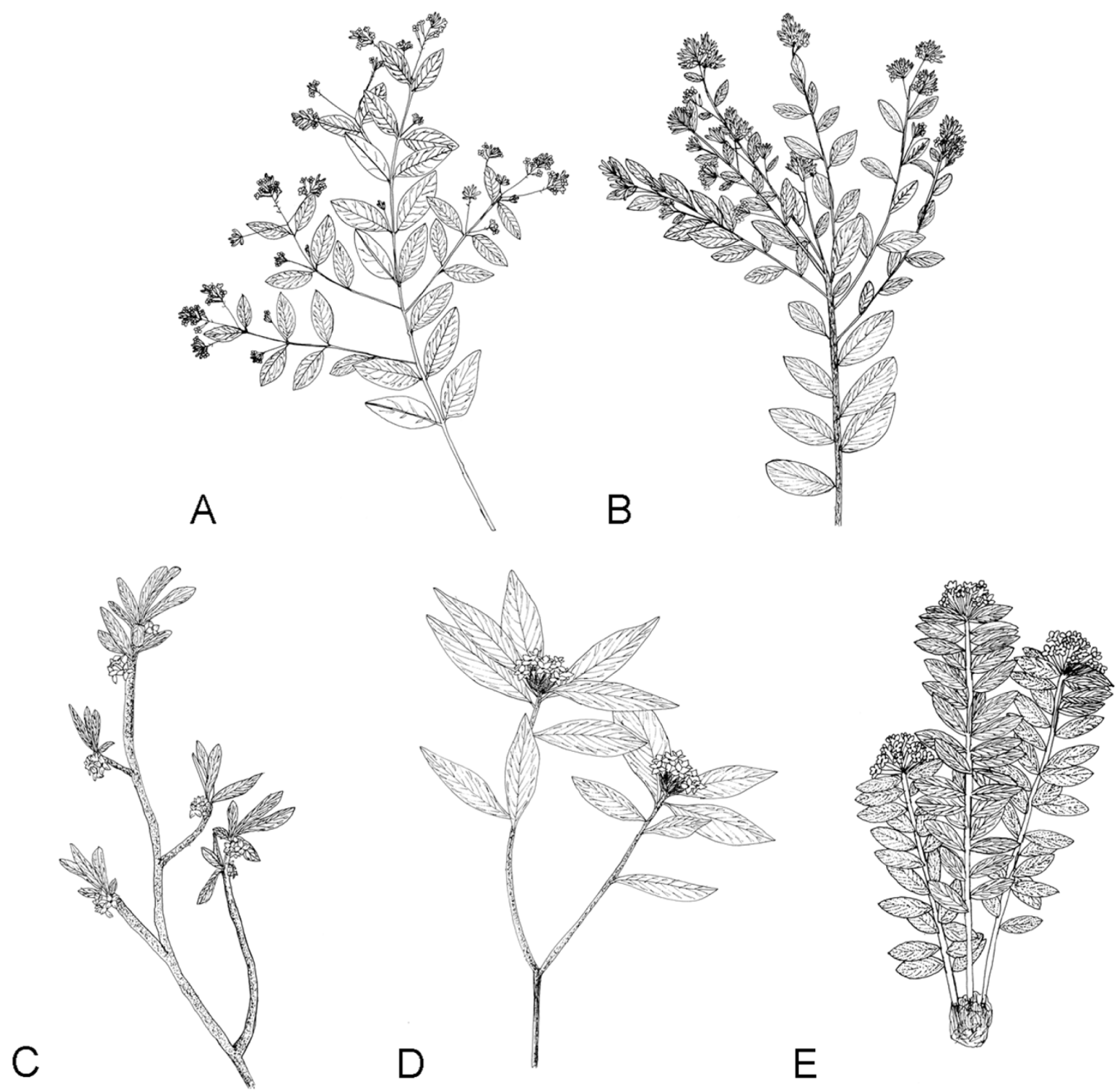

Fig. 1. Branching patterns of Thymelaeaceae in Korea. A. Wikstroemia type found in Daphne genkwa, and Wikstroemia trichotoma. B. Diplomorpha type in Diarthron linifolium and Wikstroemia ganpi. C. Mezereum type in Daphne pseudomezereum var. koreana. D. Edgeworthia type in Daphne jejudoensis, D. kiusiana, D. odora, and Edgeworthia chrysantha. E. Stellera type in Stellera chamaejasme. 
은 잎이 호생하고 분지하는 줄기가 대칭하지 않으며, 화 서가 떨어진 마디 또는 그 하부의 2-3마디의 엽액에서 새 로운 줄기가 발달하는 형태로서 거문도닥나무(W. ganpi) 와 아마풀(Diarthron linifolium)에서 관찰되었다(Fig. 1B). Mezereum type (Hamaya, 1955)은 잎이 호생하며, 액생하는 화서가 줄기의 정단부가 아닌 중간에 위치하고, 줄기의 정단부는 축 방향으로 신장하는데 두메닥나무 $(D$. pseudomezereum var. koreana)가 이에 해당됐다(Fig. 1C). Edgeworthia type (Hamaya, 1955)은 잎이 호생하고 화서가 줄기 정단분열부 기부에 달려있으며, 개화와 결실 후 다 음 해에 줄기의 생장과 분지가 이루어지는 다른 형태와는 달리 줄기의 분지가 개화와 결실과 같은 해에 이루어진다. 제주백서향나무(D. jejudoensis), 백서향나무(D. kiusiana), 서향나무(D. odora) 및 삼지닥나무(E. chrysantha)가 이에 해당되는데 이 중 삼지닥나무(E. chrysantha)는 줄기가 분 지점으로부터 세 갈래로 분지하는 특성을 관찰할 수 있었 다(Fig. 1D). 한편 Stellera type (Hamaya, 1955)은 잎이 호생 하고 줄기 정단부에 화서가 달리나 줄기는 분지하지 않는 형태로 피뿌리풀(S. chamaejasme)에서 관찰되었다(Fig. 1E).

2. 줄기의 털: 줄기에 털이 관찰된 분류군은 팥꽃나무, 삼지닥나무 및 거문도닥나무다. 팥꽃나무와 거문도닥나 무는 누운 털이 섬유처럼 덮여있으며, 삼지닥나무는 짧은 털이 한쪽 방향으로 빽빽하게 덮여있는데 어린 줄기일수 록 더 많은 털이 관찰되었다. 줄기에 털이 없는 분류군은 제주백서향나무, 백서향나무, 서향나무, 두메닥나무, 아 마풀, 피뿌리풀 및 산닥나무다.

\section{잎(leaves)}

1. 잎의 배열: 한국산 팥꽃나무과 분류군에서는 잎의 배 열이 대생과 호생의 두 가지 유형이 나타났으며, 일반적으 로 종 내에서 한 유형만 나타났다. 다만, 팥꽃나무( $D$. genkwa)의 경우, 주로 대생하나 드물게 호생하기도 하였다. 대생은 산닥나무(W. trichotoma)에서 나타났으며, 호생은 제
주백서향나무(D. jejudoensis), 백서향나무(D. kiusiana), 서향 나무(D. odora), 두메닥나무(D. pseudomezereum var. koreana), 아마풀(Diarthron linifolium), 삼지닥나무(E. chrysantha), 피 뿌리풀(S. chamaejasme) 및 거문도닥나무(W. ganpi) 등 대 부분의 분류군에서 나타났다.

2. 잎의 형태: 본 분류군들의 잎 형태는 타원상 피침형 (elliptic-lanceolate), 도피침형(oblanceolate), 선형(linear), 장 타원상 피침형(oblong-lanceolate), 난형(ovate)의 형태를 보 였다. 타원상 피침형은 팥꽃나무와 제주백서향나무, 거문 도닥나무에서 나타났으며(Fig. 2A), 도피침형은 백서향나 무, 서향나무, 두메닥나무, 삼지닥나무에서 관찰되었다 (Fig. 2B). 선형은 아마풀에서 나타났고(Fig. 2C), 장타원상 피침형은 피뿌리풀에서 나타났다(Fig. 2D). 난형은 산닥 나무에서 관찰되었다(Fig. 2E).

3. 잎의 털: 한국산 팥꽃나무과 분류군중 팥꽃나무, 아마 풀, 삼지닥나무, 거문도닥나무의 잎에서 털이 관찰되었으 며, 털의 위치와 형태는 제각기 다르게 확인되었다(Table 1). 팥꽃나무는 잎 상면에 짧은 털이 드문드문 나 있으나 잎 하면에는 엽연과 주맥을 따라 털이 밀생하며 잎자루에 도 밀생하였다. 아마풀은 엽연에 긴 털이 드문드문 관찰 되며 잎자루에는 털이 없었다. 삼지닥나무는 잎 상면 전 면에 걸쳐 짧은 털이 엽선 방향으로 누운 채 빽빽하게 덮 여 있으나 잎 하면에는 엽맥을 따라 짧은 털이 분포하였 으며 잎자루의 표면에도 짧은 털이 빽빽하게 관찰되었다. 거문도닥나무의 잎 상면에는 엽저 부분에만 주맥을 따라 짧은 털이 드문드문 있으며 잎 하면에는 주맥과 엽연을 따라 털이 드문드문 있고, 잎자루는 털이 매우 빽빽하게 덮여 있었다. 제주백서향나무, 백서향나무, 서향나무, 두 메닥나무, 피뿌리풀 및 산닥나무는 잎이 모두 무모이다 (Table 1).

4. 잎의 크기: 본 분류군들의 잎은 길이 $0.6-14 \mathrm{~cm}$, 너비 $0.7 \mathrm{~mm}-3.5 \mathrm{~cm}$ 로 그 범위가 매우 다양하였으며, 각 분류 군별 길이 및 너비는 Table 1 에 제시하였다. 아마풀은 한국 산 팥꽃나무과에서 길이와 너비가 가장 작은 분류군으로
A

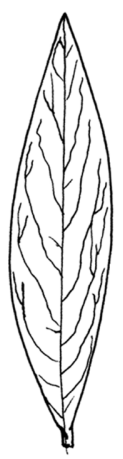

B

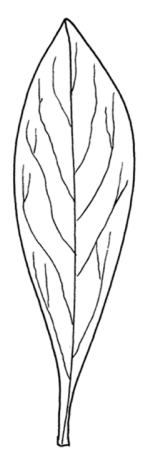

C

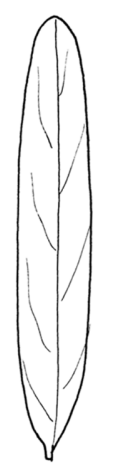

D

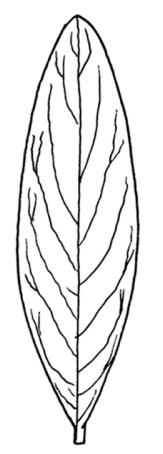

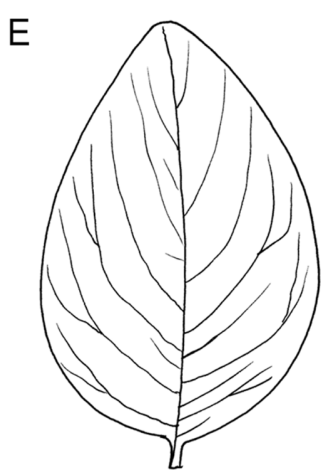

Fig. 2. Leaves shape of Thymelaeaceae in Korea. A. Elliptic-lanceolate leaves found in Daphne genkwa, D. jejudoensis, and Wikstroemia ganpi. B. Oblanceolate leaves in Daphne kiusiana, D. odora, D. pseudomezereum var. koreana, and Edgeworthia chrysantha. C. Linear leaves in Diarthron linifolium. D. Oblong-lanceolate leaves in Stellera chamaejasme. E. Ovate leaves in Wikstroemia trichotoma. 
Table 1. Leaf length and width and distribution of trichomes on leaf in the Korean Thymelaeaceae. Mean is indicated within parenthesis.

\begin{tabular}{|c|c|c|c|c|c|c|}
\hline Taxon & $\begin{array}{l}\text { Leaf length } \\
(\mathrm{cm})\end{array}$ & $\begin{array}{c}\text { Leaf width } \\
(\mathrm{cm}, \text { unless indicated) }\end{array}$ & $\begin{array}{l}\text { Adaxial } \\
\text { surface }\end{array}$ & $\begin{array}{l}\text { Abaxial } \\
\text { surface }\end{array}$ & Margin & Petiole \\
\hline Daphne genkwa & $0.9-(3.1)-4.5$ & $0.6-(1.1)-1.7$ & + & ++ & ++ & ++ \\
\hline D. jejudoensis & $7.2-(7.8)-11.0$ & $1.7-(2.1)-2.8$ & - & - & - & - \\
\hline D. kiusiana & $6.2-(7.3)-13.2$ & $1.6-(2.6)-3.5$ & - & - & - & - \\
\hline D. odora & $3.0-(5.4)-7.0$ & $1.1-(1.7)-2.2$ & - & - & - & - \\
\hline D. pseudomezereum var. koreana & $3.0-(6.7)-9.0$ & $1.4-(1.9)-2.7$ & - & - & - & - \\
\hline Diarthron linifolium & $0.6-(0.8)-1.2$ & $0.7-(1.1)-1.6 \mathrm{~mm}$ & - & + & + & - \\
\hline Edgeworthia chrysantha & $4.0-(8.0)-14.0$ & $1.9-(2.9)-3.4$ & ++ & + & ++ & ++ \\
\hline Stellaria chamaejasme & $1.5-(1.8)-2.2$ & $3-(5.1)-7 \mathrm{~mm}$ & - & - & - & - \\
\hline Wikstroemia ganpi & $1.0-(2.4)-3.2$ & $0.8-(1.2)-1.7$ & + & + & + & ++ \\
\hline W. trichotoma & $0.8-(3.0)-5.0$ & $1.2-(1.6)-2.7$ & - & - & - & - \\
\hline
\end{tabular}

-, glabrous; +, hairy; ++, densely hairy.

길이와 너비의 평균이 각각 $8 \mathrm{~mm}$ 및 $1.1 \mathrm{~mm}$ 였다. 피뿌리 풀도 잎이 작은 분류군으로 길이와 너비의 평균이 각각 $1.8 \mathrm{~cm}$ 및 $5.1 \mathrm{~mm}$ 이었다. 한국산 팥꽃나무과에서 삼지닥 나무의 잎이 가장 대형이었으며, 한 개체에서도 잎의 크 기의 변이가 매우 크게 관찰됐다. 팥꽃나무속 분류군은 산닥나무속 분류군보다 잎의 길이는 길었으며, 팥꽃나무 속 내에서는 팥꽃나무의 잎이 나머지 분류군보다 작은 경 향이 나타났다(Table 1).

한편, 최근 신종으로 발표된 제주도산 제주백서향나무 의 잎 크기를 경남 거제도 및 일본산 백서향나무와 정량 적으로 비교한 결과 제주백서향나무의 잎 크기는 다소 차 이를 보였다. 제주백서향나무의 잎 길이는 7.2-11 cm (Fig. $3 \mathrm{~A}$ ), 기부로부터 최대폭까지의 길이는 $3.2-5.6 \mathrm{~cm}$ (Fig. $3 \mathrm{~B}$ ), 잎 최대폭은 $1.7-2.8 \mathrm{~cm}$ (Fig. $3 \mathrm{C}$ ) 범위 내에서 관찰되 었다. 각 개체의 형질을 그래프에 나타낸 결과 제주도산 제주백서향나무는 경남 거제도 및 일본산 백서향나무와 비교했을 때, 동일한 길이에 대해 기부로부터 최대폭까지 의 길이가 짧은 형태임을 나타내었다(Fig. $3 \mathrm{~B})$. 이러한 결 과는 백서향나무의 잎은 피침형인 반면, 제주도산 개체들 의 잎이 타원상 피침형인 점을 들어 제주백서향나무로 기 재한 Lee et al. (2013)을 지지해 준다.

\section{화서(inflorescence)}

한국산 팥꽃나무과 분류군들은 총상(raceme), 두상 (head) 및 두상화서 모양의 산형(head-like umbel), 원추화 서(panicle)의 형태를 보였다 (Fig. 4). 총상화서는 아마풀 (Diarthron linifolium)과 거문도닥나무(W. ganpi)에서 나타 났다. 아마풀의 경우 화서는 정생하며, 화서 당 2-8 개의 꽃이 달렸으며, 거문도닥나무에서는 정생하는 화서에 10-12 개의 꽃이 달렸다. 두상화서 모양의 산형화서는 전 체 형태가 두상화서처럼 보이나 각 꽃의 소화경이 매우 짧 은 형태로, 팥꽃나무속(Daphne)에서 나타났다. 두상화서 는 삼지닥나무(E. chrysantha)와 피뿌리풀(S. chamaejasme) 에서 나타났다. 피뿌리풀의 경우 화서가 정생하나, 삼지
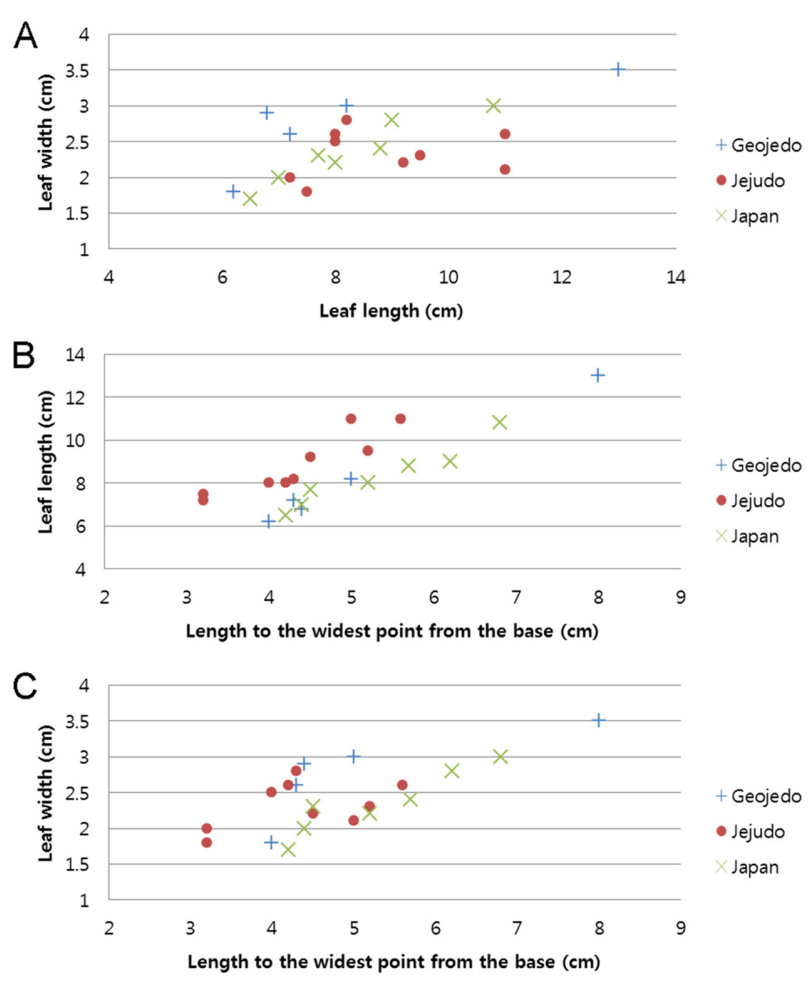

Fig. 3. Plots of leaf characters measured in Daphne kiusiana and D. iejudoensis. A. Leaf length vs. leaf width. B. Leaf length vs. length to the widest point from the base. C. Leaf width vs. length to the widest point from the base.

닥나무는 정생 또는 액생한다. 원추화서는 산닥나무 $(W$. trichotoma)에서 관찰되었으며, 정생하고, 10-15 개의 꽃이 달렸다.

\section{꽃(flowers)}

꽃은 통형으로 신장된 화탁통을 포함하고 있다. 이 구조 는 악편의 기부가 유합된 악통(calyx tube)이라는 해석과 화피와 수술의 일부가 합착된 화탁통(hypanthium)이라는 

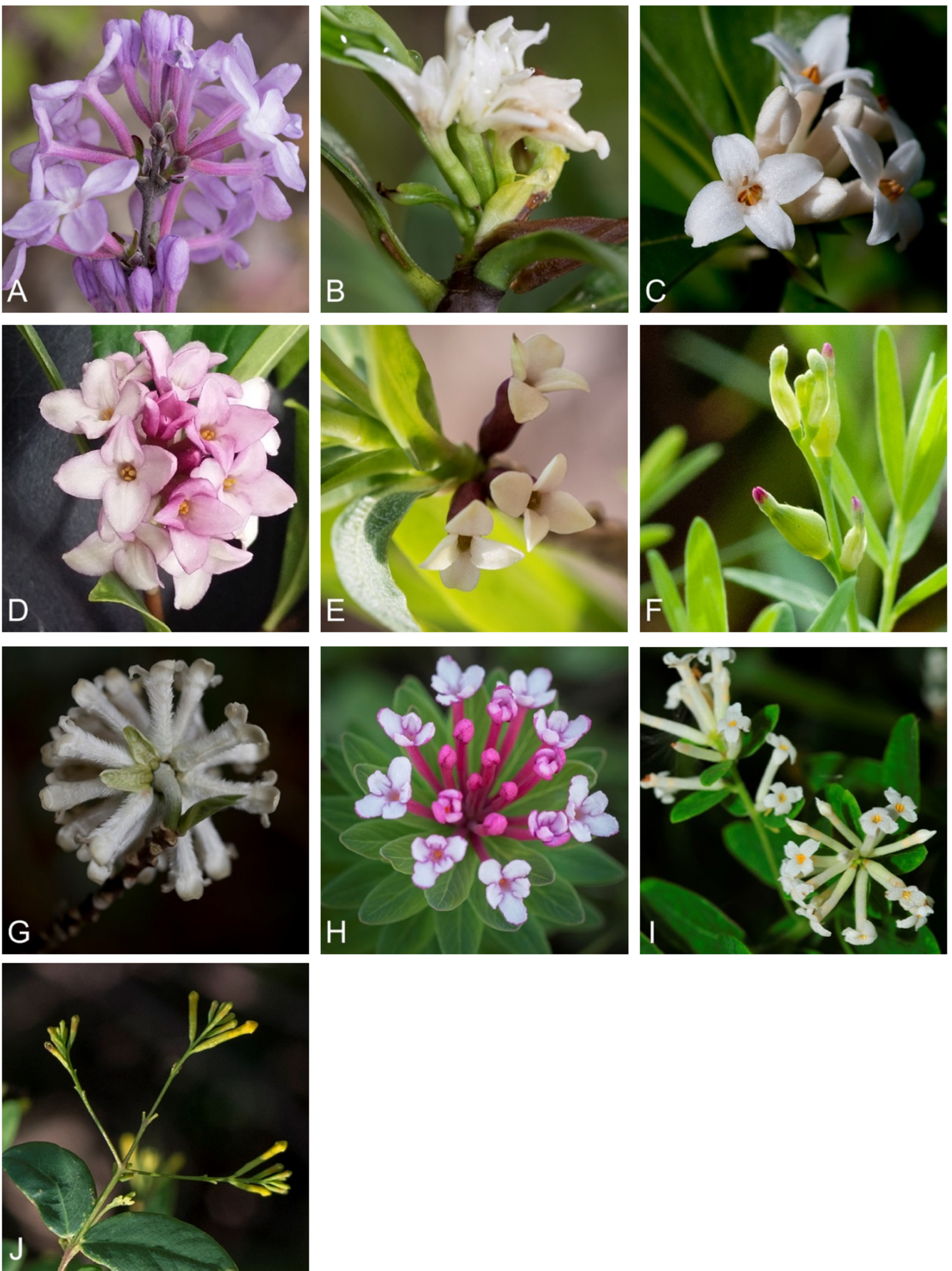

Fig. 4. Inflorescence types of Thymelaeaceae in Korea. A. Daphne genkwa. B. D. jejudoensis. C. D. kiusiana. D. D. odora. E. D. pseudomezereum var. koreana. F. Diarthron linifolium. G. Edgeworthia chrysantha. H. Stellera chamaejasme. I. Wikstroemia ganpi. J. W. trichotoma. 
견해가 있으나(Herber, 2003), 최근의 문헌에서는 화탁통 으로 여겨지고 있다(Webb and Ferguson, 1968; Bunninger, 1972; Halda, 2001). 화판(petal)은 없었다. 암술과 수술은 화 탁통 밖으로 노출되지 않았다.

1. 화탁통 및 악편의 색깔: 본 분류군들의 화탁통은 보라 색, 흰색, 연분홍색, 녹색, 황색, 자주색의 색깔이 나타났다. 일반적으로 화탁통과 악편은 동일한 색을 보였으나, 하나 의 화탁통에 두 가지의 색이 나타나거나 화탁통의 색이 악편의 색과 다른 분류군도 관찰되었다. 화탁통이 보라색 인 분류군은 팥꽃나무 $(D$. genkwa)로 연보라색이나 회보라 색이 화탁통 전체에서 발현되었다. 연분홍색이 관찰되는 분류군은 서향나무(D. odora)가 해당되며, 황색은 산닥나 무(W. trichotoma)에서 나타났다. 녹색은 아마풀(Diarthron linifolium)에서 관찰되었는데, 이 종의 악편은 자주색이었 다. 흰색이 관찰되는 분류군은 백서향나무(D. kiusiana)와 두메닥나무(D. pseudomezereum var. koreana), 삼자닥나무 (E. chrysantha) 및 거문도닥나무(W. ganpi)로 이 중 두메닥 나무는 화탁통 하부로 갈수록 점차 갈색이 관찰되었고, 삼지닥나무는 화탁통 외부는 흰색이나 악편 부분은 황색 이 관찰되었다. 제주백서향나무 $(D$. jejudoensis $)$ 에서도 흰 색이 관찰되었으며, 화탁통 하부로 갈수록 점차 녹색이 나타났고, 자주색은 피뿌리풀(S. chamaejasme)에서 관찰 되었으며 악편은 연분홍색이 관찰되었다. 중국, 몽골, 네 팔 및 러시아에 분포하는 피뿌리풀(S. chamaejasme)에서 는 흰색과 황색의 화탁통도 나타나나, 한반도 개체군(제 주도)에서는 자주색만 나타났다.

2. 화탁통의 길이와 악편의 개수: 화탁통의 길이는 2$15 \mathrm{~mm}$ 로 그 범위가 다양하였다. 제주백서향나무의 화탁 통 길이가 12-14 mm로 나타났으며, 삼지닥나무는 10$14 \mathrm{~mm}$ 로 나타났고, 백서향나무(D. kiusiana)는 7-15 mm까 지 관찰되었다. 아마풀은 2-3 mm로 한국산 팥꽃나무과 식물 중 가장 작은 것으로 관찰되었으며, 두메닥나무는 4-5 mm로 나타났고, 산닥나무는 6-8 mm로 관찰되었다. 팥꽃나무, 서향나무, 피뿌리풀, 거문도닥나무는 8-12 mm 범위 내에서 다양한 크기의 변이를 보였다.

한국산 팥꽃나무과의 악편은 대부분 4 개였으나, 피뿌 리풀에서는 5 개였고, 간혹 4 개인 꽃이 관찰되었다.

3. 화탁통의 털: 한국산 팥꽃나무과에서 화탁통에 털이 있는 분류군은 팥꽃나무, 백서향나무, 아마풀, 삼자닥나 무 및 거문도닥나무다. 제주백서향나무, 서향나무, 두메 닥나무, 피뿌리풀 및 산닥나무의 화탁통에서는 털이 관찰 되지 않았다.

한편 백서향나무의 경우 경남 거제도와 일본에 분포하 는 개체에서는 털이 관찰되었으나 제주도에서 채집된 개 체에서는 털이 관찰되지 않았다. Lee et al. (2013)은 이러한 백서향나무의 화탁통의 털 유무에 대해 털이 없는 제주도 산 개체를 백서향나무와 구분하여 제주백서향나무로 독 립된 종으로 인식하였다.

\section{수술(stamens)}

본 분류군의 수술 개수는 4 개, 8 개, 10 개의 3 가지 유형으 로 구분되었는데 아마풀(Diarthron linifolium)은 4개, 피뿌 리풀(S. chamaejasme)은 10 개, 팥꽃나무 $(D$. genkwa), 제주 백서향나무 (D. jejudoensis), 백서향나무(D. kiusiana), 서향 나무(D. odora), 두메닥나무(D. pseudomezereum var. koreana), 삼지닥나무(E. chrysantha), 거문도닥나무(W. ganpi) 및 산닥나무(W. trichotoma)는 8개로 나타나 수술의 수는 4 의 배수와 5 의 배수로 구성되며 일부 속 간에 뚜렷 한 차이를 나타냈다.

또한, 수술은 대부분 2 열로 배열되어 수술이 8 개인 분류 군에서는 수술이 4 개씩 2 열, 수술이 10 개인 종에서는 5 개 씩 2열로 배열되었다. 아마풀은 수술 4 개가 1 열로 배열된 형태를 보였다. 한 열 내의 수술 개수와 악편의 개수는 일 치하는 것으로 확인됐다.

수술대의 길이는 $0.2-1 \mathrm{~mm}$ 범위로 관찰되었으며 두메 닥나무는 $0.2 \mathrm{~mm}$ 로 가장 짧았고, 제주백서향나무, 아마풀, 거문도닥나무, 산닥나무 및 피뿌리풀이 $0.5 \mathrm{~mm}$ 로 관찰되 었다. 팥꽃나무, 백서향나무, 서향나무 및 삼지닥나무는 $1 \mathrm{~mm}$ 로 관찰되었다.

\section{암술(pistil)}

1. 자방의 형태와 털: 본 분류군의 자방 형태는 도피침형 과 장타원형으로 구분된다(Fig. 5). 도피침형(oblanceolate) 자 방은 팥꽃나무(D. genkwa), 거문도닥나무(W. ganpi) 및 산닥 나무(W. trichotoma)에서 관찰되었다. 장타원형(oblong) 자방 은 제주백서향나무(D. jejudoensis), 백서향나무(D. kiusiana), 서향나무(D. odora), 두메닥나무(D. pseudomezereum var. koreana), 삼지닥나무 $(E$. chrysantha) 및 피뿌리풀 $(S$. chamaejasme)에서 관찰되었다.

자방에 털이 관찰된 분류군은 팥꽃나무, 삼지닥나무, 거 문도닥나무 및 산닥나무이며, 팥꽃나무는 자방 상부에 털 이 집중되어 있었고, 산닥나무는 털이 매우 성기게 나타 났다. 아마풀은 자방의 크기가 매우 작아 해부현미경으로 그 형태와 털의 유무를 확인할 수 없었다(Fig. 5).

2. 암술대 길이: 암술대의 길이는 $0.2-3 \mathrm{~mm}$ 로 그 범위가 다양하였다. 아마풀은 $0.8-1 \mathrm{~mm}$ 로 한국산 팥꽃나무과에 서 가장 짧았으며, 삼지닥나무는 $3 \mathrm{~mm}$ 로 가장 길었다. 나 머지 팥꽃나무, 제주백서향나무, 서향나무, 백서향나무, 두메닥나무, 피뿌리풀, 거문도닥나무 및 산닥나무는 모두 $0.2-0.4 \mathrm{~mm}$ 범위 이내로 관찰되었다.

\section{화반(disk)}

화반의 형태는 팥꽃나무과 분류군을 구분하는 데 중요 한 형태형질로 사용되어 왔으며, 특히 화반의 형태에 근 거해 팥꽃나무속(Daphne)과 산닥나무속(Wikstroemia)을 구분하여 왔다(Domke, 1932; Hamaya, 1955; Halda, 1998).

한국산 팥꽃나무과의 분류군에서 화반 형태는 컵(cup) 

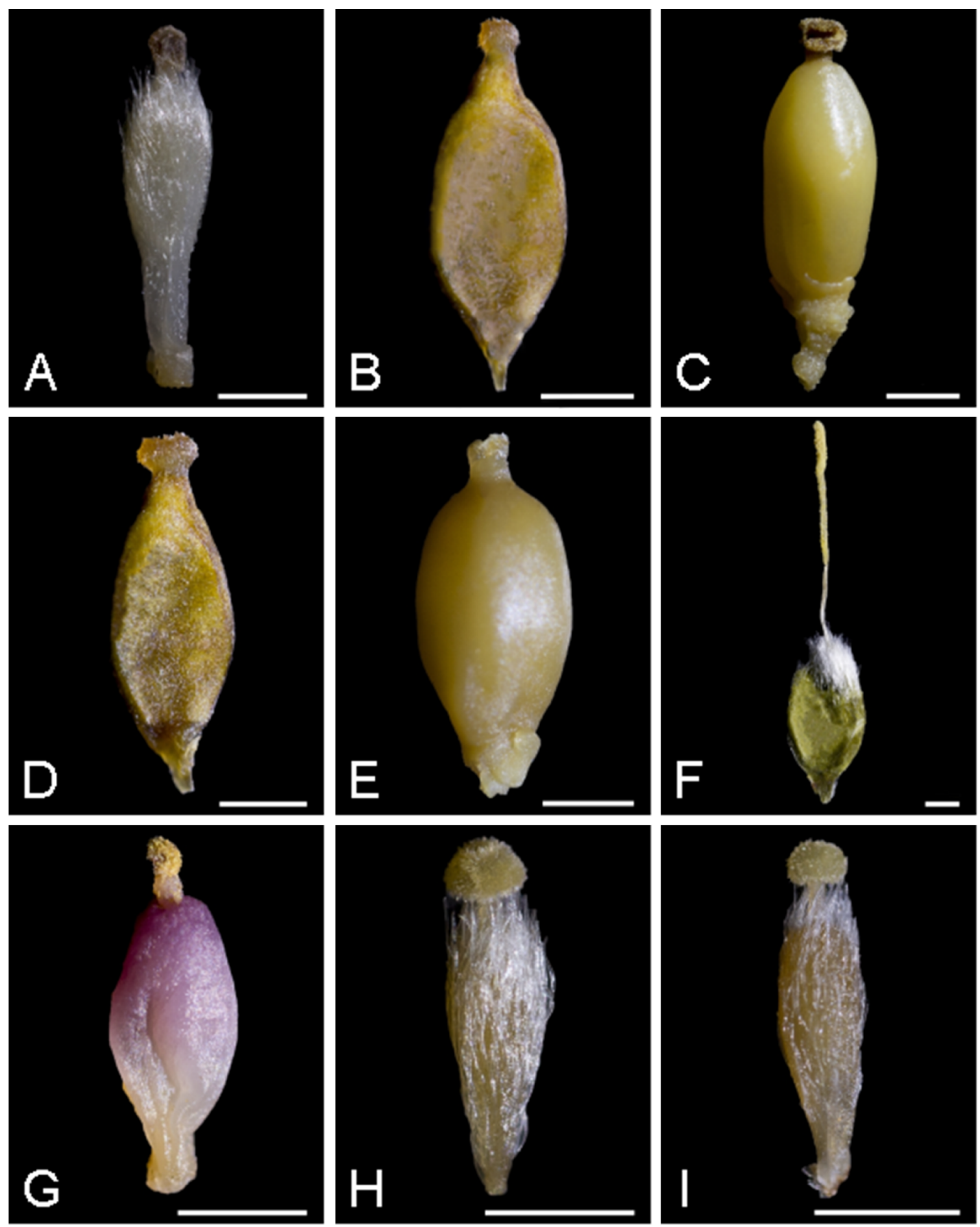

Fig. 5. Ovary of Thymelaeaceae in Korea. A. Daphne genkwa. B. D. jejudoensis. C. D. kiusiana. D. D. odora. E. D. pseudomezereum var. koreana. F. Edgeworthia chrysantha. G. Stellera chamaejasme. H. Wikstroemia ganpi. I. W. trichotoma.

모양, 비늘(scale) 모양, 고리(annular) 모양으로 구분된다 (Fig. 6). 컵 모양은 자방의 기부를 컵이나 사발 형태의 화 반이 감싼 형태로 팥꽃나무 $(D . g e n k w a)$, 제주백서향나무 (D. jejudoensis), 백서향나무(D. kiusiana) 및 서향나무(D. odora)에서 관찰됐다. 이들 종에서 나타나는 컵 모양의 화 반은 선단부가 불규칙적이며, 울통불통하나, 깊게 갈라지 지 않는다. 반면, 삼지닥나무(E. chrysantha)는 컵 모양에 가까운 형태를 보이나, 화반이 깊게 갈라진 특징이 있는 


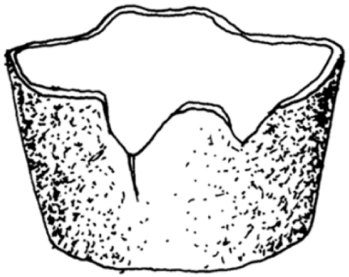

A

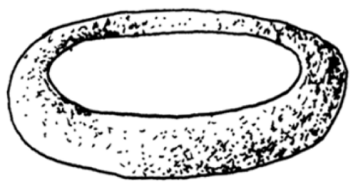

D

G

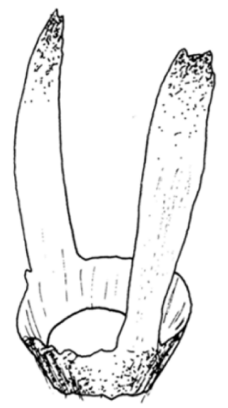

B
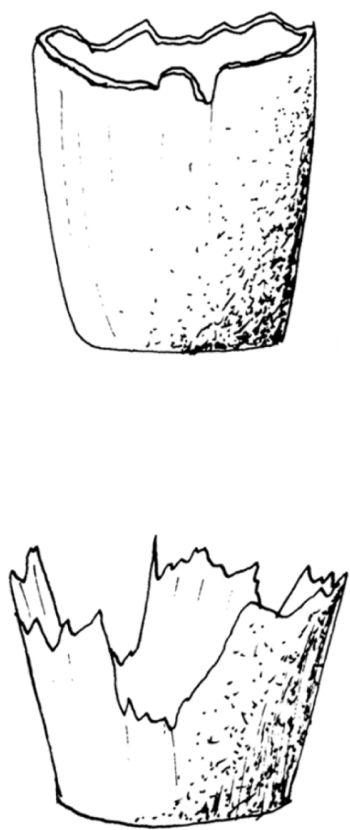

E

$\mathrm{F}$

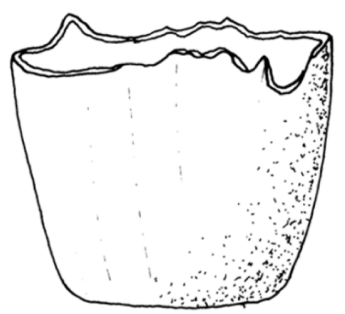

C

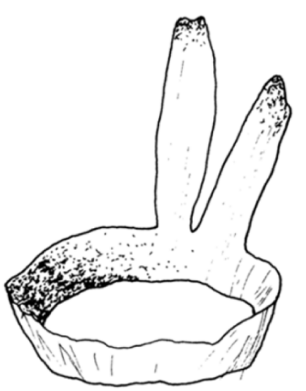

$\mathrm{H}$

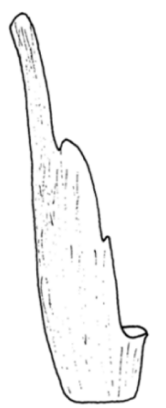

Fig. 6. Shape of disk of Thymelaeaceae observed in Korea. A. Daphne genkwa. B. D. jejudoensis. C. D. kiusiana. D. D. odora. E. Edgeworthia chrysantha. F. Stellea chamaejasme. G. Wikstroemia ganpi. H. W. trichotoma.

것으로 나타났다. 비늘 모양은 1-2개의 선형 또는 피침형 의 열편이 있는 형태로서 피뿌리풀(S. chamaejasme), 거문 도닥나무(W. ganpi) 및 산닥나무(W. trichotoma)에서 관찰됐 다. 고리 모양의 화반은 자방의 기부를 원형으로 감싸며 가 장자리가 매끈한 형태로서 두메닥나무(D. pseudomezereum var. koreana)에서 나타났다. 아마풀(Diarthron linifolium)은 화반의 크기가 매우 작아 그 형태를 관찰할 수 없었다.

\section{열매(fruit)}

한국산 팥꽃나무과의 열매는 모두 핵과인 것으로 나타 났다. 분류군에 따라서 과피가 육질인 것과 건성인 것으로 구분되었다. 한국산 팥꽃나무과의 대부분의 분류군은 과 피가 건성이나 팥꽃나무 $(D . g e n k w a)$ 를 제외한 팥꽃나무속
(Daphne) 분류군(제주백서향나무[D. jejudoensis], 백서향나 무[D. kiusiana], 두메닥나무 [D. pseudomezereum var. koreana] 및 서향나무 [D. odora)])은 육질의 과피를 나타냈다.

\section{고 찰}

\section{한국산 팥꽃나무과의 속 분류}

비교형태학적 연구 결과 한국산 팥꽃나무과 분류군들은 속 및 종 수준에서 대부분 뚜렷이 구분되어 각각을 인식하 는 데 혼란이 없는 것으로 판단된다(Table 2). 한국산 팥꽃나 무과는 팥꽃나무속(Daphne)과 산닥나무속(Wikstroemia)을 제외하면 3속(삼지닥나무속, 아마풀속 및 피뿌리풀속)이 1 종씩만 생육하는 비교적 다양성이 작은 과이고 각 종의 
Table 2. Comparison of key morphological characters of Thymelaeaceae in Korea. For branching pattern refer to Fig. 1.

\begin{tabular}{|c|c|c|c|c|c|c|}
\hline Taxon & Habit & Branching pattern & Leaf arrangement & Leaf shape & Inflorescence & Flower color \\
\hline Daphne genkwa & Deciduous shrubs & Wikstroemai type & $\begin{array}{c}\text { Opposite, } \\
\text { rarely alternate }\end{array}$ & Elliptic-lanceolate & Head-like umbel & Purple \\
\hline D. jejudoensis & Evergreen shrubs & Edgeworthia type & Alternate & Elliptic-lanceolate & Head-like umbel & White \\
\hline D. kiusiana & Evergreen shrubs & Edgeworthia type & Alternate & Oblanceolate & Head-like umbel & White \\
\hline D. odora & Evergreen shrubs & Edgeworthia type & Alternate & Oblanceolate & Head-like umbel & Pale pink \\
\hline D. pseudomezereum var. koreana & Evergreen shrubs & Mezereum type & Alternate & Oblanceolate & Head-like umbel & White \\
\hline Diarthron linifolium & Annual herbs & Diplomorpha type & Alternate & Linear & Raceme & Green with purple sepals \\
\hline Edgeworthia chrysantha & Evergreen shrubs & Edgeworthia type & Alternate & Oblanceolate & Head & White with yellow sepals \\
\hline Stellera chamaejasme & Perennial herbs & Stellera type & Alternate & Oblong-lanceolate & Head & Purple with pink sepals \\
\hline Wikstroemia ganpi & Evergreen shrubs & Diplomorpha type & Alternate & Elliptic-lanceolate & Raceme & White \\
\hline W. trichotoma & Evergreen shrubs & Wikstroemai type & Opposite & Ovate & Panicle & Yellow \\
\hline
\end{tabular}

Table 2. Continued.

\begin{tabular}{|c|c|c|c|c|c|c|}
\hline Taxon & $\begin{array}{l}\text { Hypanthium length } \\
(\mathrm{mm})\end{array}$ & $\begin{array}{c}\text { Hypanthium } \\
\text { pubescence }\end{array}$ & Merosity & Number of stamens & Ovary shape & Disk \\
\hline Daphne genkwa & $8-12$ & Hairy & 4 & 8 & Oblanceolate & Cup-shape \\
\hline D. jejudoensis & $12-14$ & Glabrous & 4 & 8 & Oblong & Cup-shape \\
\hline D. kiusiana & $7-15$ & Hairy & 4 & 8 & Oblong & Cup-shape \\
\hline D. odora & $8-12$ & Glabrous & 4 & 8 & Oblong & Cup-shape \\
\hline D. pseudomezereum var. koreana & $4-5$ & Glabrous & 4 & 8 & Oblong & Annular \\
\hline Edgeworthia chrysantha & $10-14$ & Hairy & 4 & 8 & Oblong & Cup-shape \\
\hline Stellera chamaejasme & $8-12$ & Glabrous & 5 & 10 & Oblong & Scale-like \\
\hline Wikstroemia ganpi & $6-8$ & Hairy & 4 & 8 & Oblanceolate & Scale-like \\
\hline W. trichotoma & $8-12$ & Glabrous & 4 & 8 & Oblanceolate & Scale-like \\
\hline
\end{tabular}


한반도 내에서 분포가 제한적이다. 삼지닥나무속 (Edgeworthia)은 종이 제작을 위해 제주도를 비롯하여 남 부지방에 재배하는 1종이 한반도에 분포하며, 줄기가 뚜 렷이 3갈래 분지하고(Fig. 1), 화탁통에 털이 밀생하고, 암 술대가 길게 신장하는 특징으로 한국산 팥꽃나무과의 다 른 분류군과 뚜렷이 구분된다(Fig. 5, Table 2). 아마풀속 (Diarthron) 및 피뿌리풀속(Stellera)은 초본으로 목본인 한 반도의 다른 팥꽃나무과 분류군과 구분된다. 아마풀속은 1년생 초본인 반면, 피뿌리풀속은 지하경이 있는 다년생 초본인 점에서 쉽게 구분된다. 또한, 아마풀속은 총상화 서를 이루며, 4수성 꽃을 갖는 반면, 피뿌리풀속은 두상화 서를 이루며, 5 수성 꽃을 갖는 점에서 뚜렷이 구분된다 (Fig. 4, Table 2). 아마풀은 강원도와 충청북도의 석회암지 역에 제한적으로 분포한다. 피뿌리풀은 제주도 동부의 일 부 오름에서 자라고 있으나, 남획과 서식지의 환경 변화 로 인해 자생하는 개체수가 매우 드물다. 팥꽃나무속은 관목으로, 줄기가 뚜렷하게 3 갈래로 갈리지 않고, 두상화 서 모양의 산형화서를 가지며, 컵 또는 고리 모양의 화반 을 갖는 점에서 구분되며, 산닥나무는 관목으로 총상 또 는 원추화서를 가지며, 비늘 모양의 화반이 있는 특징으 로 뚜렷이 구분된다(Table 2).

한국산 팥꽃나무과 분류군을 모두 포함하는 Daphne group (Herber, 2003)의 계통적 유연관계는 Van der Bank et al. (2002)의 아프리카 종을 중심으로 한 팥꽃나무과의 계 통학적 연구에서만 제한적으로 보여주었다. 이 연구에서 는 Daphne, Wikstroemia, Edgeworthia 및 Stellera에서 1종씩 만 포함하였는데, 팥꽃나무과의 명확한 계통적 유연관계 와 형태형질의 진화를 이해하기 위해서는 보다 많은 분류 군과 분자형질을 이용한 연구가 요구된다.

\section{팥꽃나무(D. genkwa)의 분류학적 위치}

팥꽃나무속과 산닥나무속은 현재까지 잎의 배열, 화서 의 유형, 화반의 형태로 구분되어 왔다(Table 3). 한국산 분 류군만 고려하면, 두상화서 모양의 산형화서와 컵 또는 고리 모양의 화반을 갖는 팥꽃나무속은 총상 또는 원추화 서와 비늘 모양의 화반을 갖는 산닥나무속과 뚜렷이 구분 할 수 있으나(Figs. 4, 6), 외국의 종들을 포함하면 화서의 유형으로 두 속을 구분하는 것은 매우 어렵다(Wang et al., 2007). 화반 형태의 경우, 팥꽃나무속에서 나타나는 컵 모 양의 화반이 선단부가 깊게 갈라지는 형태를 갖는 종도 있으며, 산닥나무속에서 나타나는 비늘 모양의 화반도 비 늘이 여러 개가 기부에서 융합된 경우도 있는데 이러한 형태는 팥꽃나무속에서 나타나는 컵 모양의 화반과 비슷 하여 화반의 형태로 두 속을 명확히 구분하기가 매우 어 렵다. 그럼에도 불구하고 상기한 형질의 조합으로 두 속 을 구분하여 인식하고 있으나(Ohwi, 1965; Wang et al., 2007; Hong, 2007), 많은 수의 분류군을 포함해 두 속의 한 계에 대한 연구는 미흡한 실정이다. 예를 들면, 팥꽃나무
Table 3. Comparison of key morphological characters of Daphne and Wikstroemia Character state in parenthesis represents additional states from non-Korean taxa.

\begin{tabular}{|c|c|c|}
\hline Character & Daphne & Wikstroemia \\
\hline Habit & $\begin{array}{l}\text { Shrubs, } \\
\text { (small trees) }\end{array}$ & $\begin{array}{c}\text { Shrubs, } \\
\text { (small trees, herbs) }\end{array}$ \\
\hline Leaves arrangement & Alternate, opposite & Alternate, opposite \\
\hline Inflorescence type & $\begin{array}{l}\text { Head-like umbel, } \\
\text { (spike, panicle) }\end{array}$ & $\begin{array}{l}\text { Raceme, panicle, } \\
\text { (spike) }\end{array}$ \\
\hline Disk shape & $\begin{array}{l}\text { Cupulate, annular, } \\
\text { (scale-like, absent) }\end{array}$ & Scale-like \\
\hline Fruit type & $\begin{array}{l}\text { Drupe, fleshy or } \\
\text { dry and leathery }\end{array}$ & Drupe, fleshy or dry \\
\hline
\end{tabular}

는 잎이 대생하고, 잎에 털이 밀생하며, 자방이 도피침형 인 점에서 한국산 팥꽃나무속의 다른 종들과 뚜렷이 구분 되는데, 이러한 팥꽃나무의 특징은 산닥나무속에 가깝다. 본 논문의 제 1 저자는 석사학위 연구의 일환으로 핵 리보 오솜 ITS 구간 및 엽록체 $r b c L$ 과 $m a t K$ 구간의 염기서열을 이용한 한국산 팥꽃나무과의 계통분석을 수행하였다 (Lee, 2015). 그 결과 팥꽃나무속이 단계통군이 아니며, 팥 꽃나무가 산닥나무속에 포함되는 것으로 나타났다. 이 분 자형질 분석에 포함된 분류군 수가 제한적이므로 명확한 결론을 내리기 힘들지만, 본 연구의 형태형질 분석 결과 를 지지한다. 또한, 한국산 팥꽃나무과의 화분형태학적 연구에서(Jung and Hong, 2003a)도 팥꽃나무는 팥꽃나무 속의 다른 종들과 뚜렷하게 구분되었으며, 표피 미세구조 형질을 조사한 연구(Jung and Hong, 2003b)에서도 팥꽃나 무는 한국산 산닥나무속의 두 종과 유사한 형태임을 밝힌 바 있어서 팥꽃나무의 정확한 분류학적 위치를 비롯하여 팥꽃나무속과 산닥나무속의 한계를 설정하는 보다 자세 한 연구가 필요한 것으로 사료된다.

\section{제주백서향나무(D. jejudoensis)와 백서향나무(D. kiusiana)}

본 연구에서는 거제도산 및 일본산 백서향나무와 최근 신종 발표된 제주도의 제주백서향나무(Lee et al., 2013) 개 체에 대한 비교형태학적 연구를 수행하였다. 그 결과, 제 주백서향나무는 잎의 형태가 타원상 피침형으로 거제도 산 및 일본산의 도피침형과 확연한 차이를 보였다(Fig. 3). 또한, 거제도산 및 일본산 백서향나무는 화탁통에 털이 분포하는 반면, 제주도 개체는 화탁통이 무모인 점에서 제주백서향나무가 백서향나무와 뚜렷이 구분되는 것으 로 나타났다. 이러한 결과는 최근 백서향나무를 대상으로 분자 마커를 개발한 연구(Lee et al., 2017)의 결과를 지지한 다. Lee et al. (2017)은 거제도산 백서향나무 2개 개체군과 제주도의 제주백서향나무 개체들을 포함하여 총 19 개 마 커에 근거한 Neighbor-Joining 계통수에서 거제도산 백서 
향나무와 제주도산 제주백서향나무는 bootstrap value가 $100 \%$ 로 뚜렷하게 구분되는 것으로 밝힌 바 있다. 그러나 팥꽃나무속 내에서 제주백서향나무와 백서향나무 및 서 향나무와의 유연관계 및 팥꽃나무속 내에서 제주백서향 나무의 계통학적 위치에 대해서는 추가적인 연구가 이루 어져야 할 것으로 사료된다.

\section{거문도닥나무(W. ganpi)의 집단 간 다양성}

한편, 국립생물자원관에 소장된 표본 중 전남 여수시 상 백도에서 채집된 거문도닥나무 개체(Kim et al., 12029, $\mathrm{KB} 414351)$ 는 잎이 호생하고, 줄기와 엽병, 잎, 화탁통에 털이 있으며, 원추화서인 점에서 한반도 내 다른 개체군 인 경남 기장 및 전남 거문도에서 채집된 개체들과 동일 하였으나(Table 2), 잎의 형태가 난형이며, 크기가 크고, 잎 의 두께가 상대적으로 두꺼운 뚜렷한 차이를 보였다. 이 러한 지역별 형태형질의 차이가 무인도의 암벽에서 자라 는 환경적 특성에서 기인한 생태형인지, 상백도 개체군이 계통적으로 분화된 분류군인지 보다 자세한 연구가 필요 한 것으로 사료된다.

\section{Acknowledgments}

We are grateful to Drs. Chan Soo Kim, Byeong Yoon Lee, and T. Yukawa for allowing examination of the specimens and Hwa-Jung Suh, Dong-Hyuk Lee, Seon-Won Seo, Jung-Hee Kim, Sang-Kyung Kim, and Drs. Hyeok-Jae Choi and Myeong-Hae Kwak for helping fieldwork and obtaining samples for this study. This research was supported in part by a grant from the National Institute of Biological Resources (NIBR), funded by the Ministry of Environment (MOE) of the Republic of Korea (NIBR 201513201).

\section{Literature Cited}

Bentham, G. and J. D. Hooker. 1880. Genera Plantarum. Vol. 3. Lovell Reeve \& Co, London, 1,258 pp.

Bunninger, L. 1972. Untersuchungen über die morphologische Natur des Hypanthiums bei Myrtales- und Thymelaeales-Familien. Beiträge zur Biologie der Pflanzen 48: 79-156.

Domke, W. 1932. Zur Kenntnis einiger Thymelaeaceen. Notizblatt des Botanischen Gartens und Museums zu BerlinDahlem 11: 348-363. (in German)

Domke, W. 1934. Untersuchungen über die systematische and geographische Gliederung der Thymelaeaceen. Bibliotheca Botanica 111: 1-151. (in German)

Halda, J. J. 1998. Some taxonomic problems in the genus Daphne L. Acta Musei Richnoviensis Sect. Natur Ruchnov nad Kneznou 5: 133-160.
Halda, J. J. 2001. The genus Daphne. Sen, Dobré, 231 pp.

Hamaya, T. 1955. A dendrological monograph of the Thymelaeaceae plants of Japan. Bulletin of the Tokyo University Forests 50: 45-96.

Herber, B. E. 2003. Thymelaeaceae. In The Families and Genera of Vascular Plants. Vol. 5. Kubitzki, K and C. Bayer (eds.), Springer-Verlag, New York. Pp. 373-396.

Heywood, V. H. 1993. Flowering Plants of the World. Oxford University Press, London, 336 pp.

Hong, H.-H., H.-T. Im and S.-G. Hong. 1999. One species of Korean Wikstroemia (Thymelaeaceae): W. ganpi (Sieb. et Zucc.) Maxim. Korean Journal of Plant Taxonomy 29: 391396. (in Korean)

Hong, S.-P. 2007. Thymelaeaceae. In The Genera of Vascular Plants of Korea. Park, C.-W. (ed.), Academy Publishing Co., Seoul. Pp. 633-636.

Jung, E.-H. and S.-P. Hong. 2003a. Pollen morphology of Thymelaeaceae in Korea. Korean Journal of Plant Taxonomy 33: 255-270. (in Korean)

Jung, E.-H. and S.-P. Hong. 2003b. The taxonomic consideration of leaf epidermal microstructure in Korean Thymelaeaceae Adans. Korean Journal of Plant Taxonomy 33: 421-433. (in Korean)

Lee, J., K.-H. Lee, S. So, C. Choi and M. Kim. 2013. A new species of Daphne (Thymelaeaceae): D. jejudoensis M. Kim. Korean Journal of Plant Taxonomy 43: 94-98.

Lee, J.-H., W.-B. Lee, S. Yang, E.-K. Han, E.-S. Lyu, W. J. Kim, B. C. Moon and G. Choi. 2017. Development and characterization of 21 microsatellite markers in Daphne kiusiana, an evergreen borad-leaved shrub endemic to Korea and Japan. Korean Journal of Plant Taxnomy 47: 11-22.

Lee, J.-J. 2015. Phylogenetic Systematics of Thymelaeaceae in Korea. M.S. thesis, Daejeon University, Daejeon, Korea, 105 pp.

Lee, T. B. 2003. Coloured Flora of Korea. Hyangmunsa, Seoul, Vol. 1, 914 pp. (in Korean)

Mabberley, D. J. 1997. The Plant-Book. 2nd ed. Cambridege University Press, Cambridge, 874 pp.

Ohwi, J. 1965. Flora of Japan. Smithsonian Institution, Washington, D.C., 1067 pp.

Takhtajan, A. 1997. Diversity and Classification of Flowering Plants. Columbia University Press, New York, 620 pp.

Van der Bank, M., M. F. Fay and M. W. Chase. 2002. Molecular phylogenetics of Thymelaeaceae with particular reference to African and Australian genera. Taxon 51: 329-339.

Wang, Y., M. G. Gilbert, B. Mathew, C. D. Brickell and L. I. Nevling. 2007. Thymelaeaceae. In Flora of China. Vol. 13. Clusiaceae through Araliaceae. Wu, Z. Y., P. H. Raven and D. 
Y. Hong (eds.), Science Press, Beijing and Missouri Botanical Garden, St. Louis, MO. Pp. 213-250.

Webb, D. A. and I. K. Ferguson. 1968. Thymelaeaceae. In Flora of
Europaea. Vol. 2. Tutin, T. G., V. H. Heywood, N. A. Burges, D. M. Moore, D. H. Valentine, S. M. Walters and D. A. Webb (eds.), Cambridge University Press, Cambridge. Pp. 256-261.

\section{Appendix 1. A list of specimens examined in this study.}

\section{Daphne jejudoensis M. Kim (제주백서향나무)}

KOREA. Jeju-do: Jeju-si, Aewol-eup, Bongseong-ri, Mureung Gotjawal, Saebyeoloreum, 4 Mar 2011, E.S. Jeon s.n. (KB); Jejusi, Aewol-eup, Bongseong-ri, Mureung Gotjawal, Saebyeoloreum, 10 Apr 2011, E.S. Jeon s.n. (KB); Jeju-si, Gujwa-eup, Gimnyeong-ri, Myosanbong, 3 Apr 2003, M.O. Moon s.n. (WTFRC); Jeju-si, Hangyeong-myeon, Cheongsu-ri, Cheongsugotjawal, 30 May 2012, W.J. Hyeon et al. 34484, 34488, 34517 (WTFRC); Hangyeong-myeon, Cheongsu-ri, Cheongsugotjawal, 30 Mar 2012, W.J. Hyeon 34492 (KB); Jeju-si, Hangyeong-myeon, Jeoji-ri, 18 Feb 2001, C.S. Kim s.n. (WTFRC); Jeju-si, Hangyeongmyeon, Jeoji-ri, Jeojigotjawal, 31 May 2012, K.M. Song 34541 (WTFRC); Jeju-si, Jeju-si, Dongbaegdongsan, 3 Jul 2014 , S.H. Oh 9075, 9078 (TUT); Seogwipo-si, Andeok-myeon, Seogwangseo-ri, 7 Mar 2002, C.S. Kim s.n. (WTFRC); Seogwipo-si, Andeokmyeon, Seogwang-ri, 4 Mar 2009, J. Kim et al. 29371 (WTFRC); Seogwipo-si, Andeok-myeon, Seogwang-ri, Seogwanggotjawal, Climate change site, 4 Mar 2009, J. Kim et al. 26755 (WTFRC); Seogwipo-si, Andeok-myeon, Seogwang-ri, Seogwanggotjawal, 23 Mar 2010, J. Kim 29275 (WTFRC); Seogwipo-si, Sanghyo-dong, Donnaeko, Hasinsang-ro, 22 Mar 2012, C.S. Lee \& B.R. Lee leecs20120642 (KB).

\section{Daphne kiusiana Miq. (백서향나무)}

KOREA. Chungcheongnam-do: Chollipo Arboretum, 11 Sep 2014, J.J. Lee 9088 (TUT); Gyeongsangnam-do: Geoje-si, Nambumyeon, Jeogu-ri, 14 Mar 2015, J.J. Lee et al. 9121, 9125, 9126 (TUT); Geoje-si, Nambu-myeon, Jeogu-ri, 2 May 2015, W.J. Seo 9186 (TUT).

JAPAN. Honshu: Chiba Pref.: Awapgun, Amatsu, Todaichiba, 23 Mar 1968, S. Uehara 223542 (TNS); Koutou, Kiyosumi, 27 Mar 1963, T. Wakana 155810 (TNS); Koutou, Kiyosumi, 27 Feb 1966, K. Awa JH046574 (TNS). Hyogo Pref.: Tanba-gun, Sasagamine, 26 Apr 1936, S. Hosomi 56748 (TNS [2sheets]). Mie Pref.: Watarai-gun, Kajiya-dani Valley, 4 Apr 1996, Fujii et al. 5089 (TNS). Tottori Pref.: Iwami-gun, 5 Apr 1975, K. Iwatsuki et al. 26 (TNS). Yamaguchi Pref.: Nagato, Abu-gun, Kasekajaka, 18 Mar 1919, J. Nikai 47295 (TNS). Shikoku: Kagawa Pref.: Shodoshima, Kankakei, 28 Mar 1962, N. Soromu 19573 (TNS).

\section{Daphne odora Thunb. (서향나무)}

KOREA. Daejeon: Yongun-dong, 1 Apr 2015, J.J. Lee 9130 (TUT); Purchased from flower shop Simpol, 6 Apr 2015, J.J. Lee 9131 (TUT).

\section{Daphne pseudomezereum var. koreana (두메닥나무)}

KOREA. Gangwon-do: Jeongseon-gun, Hwaam-myeon, Hochon-ri, 1 Aug 2012, Y.C. Kim 3 (KB); Jeongseon-gun, Yeoryang-myeon, Goyang-ri, Mt. Goyangsan, 13 Jun 2012, K.H. Nam \& J.S. Kim SHY3-709 (KB); Jeongseon-gun, Mt. Seokbyeongsan, 13 Sep 2014, W.J. Suh 9091, 9092, 9093, 9094, 9095, 9096 (TUT); Jeongseon-gun, Mt. Seokbyeongsan, 25 Apr 2015, J.J. Lee et al. 9175, 9176 (TUT); Jeongseon-gun, Mt. Seokbyeongsan, 15 Aug 2015, W.J. Seo 6582, 6583, 6584, 6585, 6586 (TUT); Jeongseon-gun, Mt. Gwaebyeongsan, 25 Apr 2015, J.J. Lee et al. 9181, 9182 (TUT); Jeongseongun, Mt. Hambaeksan, 25 Apr 2015, J.J. Lee et al. 9183 (TUT); Pyeongchang-gun, Jinbu-myeon, Dongsan-ri, 6 Aug 2012 , Y.C. Kim 4 (KB); Samcheok-si, Hajang-myeon, Jungbong-ri, Mt. Cheongoksan, Teoggol, 25 Apr 1997, W.K. Park \& K.J. Yeom EN97KNU026 (KB); Taebaek-si, Changjuk-dong, Golji creek, 23 Apr 2013, J.H. Kim et al. Golji130086 (KB); Taebaeksi, Changjuk-dong, Geomnyongso, 25 Apr 2015, J.J. Lee et al. 9184, 9185 (TUT). Gyeongsangbuk-do: Yeongyang-gun, Irwol-myeon, Ori-ri, Mt. Irwolsan, 20 Sep 2008, B.K. Kwon 080920-244 (KB); Yeongyang-gun, Irwol-myeon, Ori-ri, Mt. Irwolsan, 13 Jun 2009, K.H. Nam VS249 (KB). NORTH KOREA. Yanggang-do: Samjiyon-gun, Mt. Beakdusan, Samjiyeon Lake, 19 Jun 2007, Without collector and number (KB). 
Wikstroemia trichotoma (Thunb.) Makino (산닥나무)

KOREA. Incheon: Ganghwa-gun, Gilsang-myeon, Seondu-ri, Mt. Gilsangsan, 12 Aug 2012, J.H. Kim \& S.Y. Kim Gilsang120535 (KB); Ganghwa-gun, Gilsang-myeon, Seondu-ri, Mt. Gilsangsan, 14 Aug 2012, J.H. Kim \& S.Y. Kim Gilsang120635 (KB); Ganghwa-gun, Gilsang-myeon, Seondu-ri, Mt. Gilsangsan, 22 Sep 2012, J.H. Kim \& S.Y. Kim Gilsang120806 (KB); Ganghwagun, Gilsang-myeon, Seondu-ri, Mt. Gilsangsan, 10 Nov 2012, J.H. Kim \& S.Y. Kim Gilsang121003 (KB); Ganghwa-gun, Gilsangmyeon, Seondu-ri, Mt. Gilsangsan, 6 Aug 2015, J.J. Lee 9256 (TUT); Ganghwa-gun, Hwado-myeon, Heungwang-ri, 21 Jul 2011 , Y.G. Kim \& J.C. Kang Kim, Kang 420 (KB); Cultivated plants. Chungcheongnam-do: Taean-gun, Sowon-myeon, Uihang-ri, Chollipo Arboretum, 11 Sep 2014, J.J. Lee 9090 (TUT). Gyeongsangnam-do: Gimhae-si, Sangdong-myeon, Mt. Sineosan, 20 Jan 1988 , C.W. Kim s.n. (KB); Namhae-gun, Gohyeon-myeon, Daegok-ri, Hwabangsa, 16 Sep 2014, D.H. Lee 9104, $9105,9106,9107$ (TUT). Jeollanam-do: Goheung-gun, Jeomam-myeon, Yeonbong-ri, 23 Jul 2011, H. Kim Hkim 6152 (KB); Jindo-gun, Mt. Yeogwisan, 28 Oct 2006, J.Y.Chung et al. Hkim2943 (KB); Yeongam-gun, Yeongam-eup, Mt. Wolchulsan, Miwangjae, Baramjae, 18 Jul 1999, J.Y. Chung et al. 89 (KB); Yeosu-si, Samsan-myeon, Chodo-ri, 23 Sep 2011, D.K. Kim \& W.J. Kim 347141-127, $347141-025(\mathrm{~KB})$;

Wikstroemia ganpi (Siebold \& Zucc.) Maxim. (거문도닥나무)

KOREA. Busan: Gijang-gun, Gijang-eup, Daebyeon-ri, 2 Aug 2014, H.J. Choi 9117 (TUT); Gijang-gun, Gijang-eup, Jukseongri, 29 Oct 2011, C.W. Kang 33427 (WTFRC); Gijang-gun, Gijang-eup, Daebyeon-ri, 16 Sep 2014, D.H. Lee 9097, 9098, 9099, 9100, 9101, 9102, 9103 (TUT); Gijang-gun, Gijang-eup, Daebyeon-ri, 23 Aug 2015, W.J. Seo 9258, 9259, 9260, 9261, 9262, 9263, 9264, 9265, 9266, 9267, 9268, 9269, 9270, 9271, 9272, 9273, 9274, 9275, 9276, 9277, 9278, 9279, 9280, 9281 (TUT). Jeollanam-do: Yeosu-si, Samsan-myeon, Geomun-ri, Sangbaek-do Island, 18 Aug 2012, Kim et al 12029 (KB).

Wikstroemia genkwa Siebold \& Zucc. (팥꽃나무)

KOREA. Chungcheongnam-do: Taean-gun, Sowon-myeon, Uihang-ri, Chollipo Arboretum, Sep 1987, D.O. Im \& C.H. Kim s.n. (KB); Chollipo Arboretum, 11 Sep 2014, J.J. Lee 9089 (TUT). Jeollabuk-do: Buan-gun, Byeonsan-myeon, Docheong-ri, Eonpo Village, 18 Apr 2015, J.J. Lee 9170, 9171, 9172, 9173, 9174 (TUT); Jeollanam-do: Haenam-gun, Hwangsan-myeon, on Road \#18, 16 Sep 2014, D.H. Lee 9108, 9109, 9110, 9111 (TUT); Haenam-gun, Masan-myeon, 5 May 2015, W.J. Seo 9187 (TUT); Haenam-gun, Munnae-myeon, Hakdong-ri, Usuyeong tour area, 5 May 2015, W.J. Seo 9188 (TUT); Haenam-gun, Munnae-myeon, Yongam-ri, Mt. Ongmaesan, 11 Sep 2012 P.Y. Yoon et al. s.n. (KB); Haenam-gun, Songji-myeon, Songho-ri, Ttangkkeut Village, 12 May 2011, K.H. Nam \& J.H. Kim HN1 (KB); Jindo-gun, Gunnae-myeon, Dunjeon-ri, Mt. Geumgolsan, 25 Apr 2012 , J.H. Kim \& K.H. Nam12035 (KB).

\section{Edgeworthia chrysantha Lindl. (삼지닥나무)}

KOREA. Chungcheongnam-do: Taean-gun, Sowon-myeon, Uihang-ri, Chollipo Arboretum, 11 Sep 2014, J.J. Lee 9087 (TUT). Chungcheongbuk-do: Jecheon-si, Geumseong-myeon, Geumseong, 27 Apr 2007, H.J. Kim et al. 710,714 (KB). Gyeongsangnam-do: Geoje-si, Dongbu-myeon, Mt. Nojasan, 6 Jun 1997, D.O. Lim \& I.C. Hwang 4801002 (KB); Geojesi, Dongbu-myeon, Mt. Nojasan, Mongdol Beach, 6 Jun 2009, J.K. Ahn CH45403 (KB). Jeollanam-do: Boseong-gun, Mt. Jonjaesan, 6 Apr 2003, without collector's name and number (KB); Goheung-gun, Gwayeok-myeon, Baegil-ri, Jageundombaek island, 24 Jun 2008, H.T. Im E08086 (KB); Suncheon-si, Oeseo-myeon, Nakseong-ri, 28 Apr 2006, H. Kim Hkim2343 (KB); Wando-gun, Gunoe-myeon, Daemun-ri, 16 Mar 2008, N.S. Lee et al. EWLEE080095 (KB); Wando-gun, Bogil-myeon, Buyong-ri, Univ. Jeonnam forest, 20 Aug 2011, S.Y. Park \& H.T. Im IM60821 (KB); Jeju-do: Jeju-si, Jocheon-eup, Wasanri, Dangohreum, 25 Mar 2010, K.H. Tae et al. s.n. (KB); Jeju-si, Yeon-dong, Namjoseunoreum, 5 Jul 2011, D.O. Im et al. LimD.O.336064-J0037(2) (KB); Seogwipo-si, Pyoseon-myeon, Seongeup-ri, Baegyagioreum, 15 Nov 2010, K.M. Song \& D.H. Kang1830 (KB); Seogwipo-si, Sanghyo-dong, Seondol, 7 Jun 2011, C.M. Kang 31669 (WTFRC); Seogwipo-si, Sanghyodong, Seondolseonwon, 3 Feb 2010, C.M. Kang \& J.N. Im 29124 (KB); Seogwipo-si, Sanghyo-dong, Seondolseonwon, 20 Jun 2011, I.C. Hwang 60198 (KB); Seogwipo-si, Sanghyo-dong, Seondolseonwon, 7 Apr 2015, J.J. Lee 9136, 9137, 9138, 9139 (TUT); Seogwipo-si, Sanghyo-dong, 8 Apr 2008, J.E. Kim et al. 25503 (WTFRC); Seogwipo-si, Sanghyo-dong, Warm Temperate Forest Research Center, 4 Jul. 2014, S.H. Oh 9079 (TUT); Seogwipo-si, Sanghyo-dong, Seondol, 17 Mar 2010, K.H. Tae et al. s.n. (KB261923). 
Diarthron linifolium Turcz. (아마풀)

KOREA. Chungcheongbuk-do: Danyang-gun, Maepo-eup, Seongmoon, 10 Oct 2008, K.Y. Jung AHN-en-081010-103 (KB); Danyang-gun, Maepo-eup, Eouigok-ri, Yeondi Valley, 20 Aug 2014. H.R. Na SD3-010 (TUT); Jecheon-si, Geumseong-myeon, Geumseong, 3 Oct 2014 H.J. Seo 9112, 9113, 9114, 9115, 9116 (TUT). Gangwon-do: Donghae-si, Cheongok-dong, Cheongok Cave, 7 Oct.2011, J.H. Kim \& J.S. Kim SHY2-1866 (KB); Jeongseon-gun, Bukpyeong-myeon, Mungok-ri, 21 Aug 2012 , J.H. Kim SHY3-1664 (KB); Samcheok-si, Miro-myeon, Sanggeono-ri, 24 Aug 2011, J.H. Kim \& J.S. Kim SHY2-1332 (KB); Yeongwolgun, Buk-myeon, Deoksang-ri, 14 Sep 2012, Y.C. Kim 129 (KB); Yeongwol-gun, Kim Satgat myeon, Daeya-ri, Gajae Valley, 15 Jun 2010, K.H. Nam et al. SHY629 (KB); Yeongwol-gun, Nam-myeon, Bukssang-ri, 24 Sep 2010, J.O. Hyeon et al. NAPI20101913 (KB); Yeongwol-gun, Nam-myeon, Changwon-ri, Damdae Valley, 2 Aug 2014, J.J. Lee 9080, 9081, 9082,9083 (TUT); Yeongwol-gun, Nam-myeon, Togyo-ri, 13 Oct 2010, B.Y. Lee et al. SHY2255 (KB); Yeongwol-gun, Nam-myeon, Togyo-ri, 2 Aug 2014, J.J. Lee 9084, 9085, 9086 (TUT). Gyeongsangbuk-do: Uiseong-gun, Dain-myeon, Bongjeong-ri, Mt. Bibongsan, 20 Aug 1999, J.H. Park et al. 6532 (KB).

\section{Stellera chamaejasme L. (피뿌리풀)}

KOREA. Jeju-do: Jeju-si, Gujwa-eup, Songdang-ri, Nopeunoreum, 23 May 2010, J. Kim 29479 (WTFRC); Jeju-si, Gujwa-eup, Songdang-ri, Gujwa Cemetery, 3 Jul 2014, S.H. Oh 9073 (TUT); Jeju-si, Gujwa-eup, Songdang-ri, Gujwa Cemetery, 20 May 2015 , J.J. Lee \& S.W. Han 9213 (TUT); Jeju-si, Gujwa-eup, Songdang-ri, Munseogioreum, 20 May 2015, J.J. Lee \& S.W. Han 9234, 9235, 9236, 9237, 9238 (TUT); Seogwipo-si, Pyoseon-myeon, Seong-eup-ri, 4 Jun 2001, C.S. Kim s.n. (WTFRC); Seogwipo-si, Pyoseon-myeon, Seong-eup-ri, Jwabomioleum, 9 May 2002, C.S. Kim s.n. (WTFRC). 